ISSN: p. 2354-354X e. $2354-3515$

Open Access Journal, Available Online

\title{
Media Convergence and Broadcasting Practice in Nigeria: Three Broadcast Stations in Focus
}

\author{
Osakpolor Emwinromwankhoe \\ University of Benin, Benin City, Nigeria \\ osakpolorgregory@yahoo.com
}

Received: 26 Dec. 2019 Accepted: 24 April 2020 Date of Publication: June 2020

\begin{abstract}
The debate about media convergence and its relevance in Nigeria is on-going. This study contributes to the discussion by examining how this critical construct impacts the broadcasting practice in Edo State, one of the country's 36 political subdivisions. The work adopts the mixed research method to investigate 100 survey respondents and interview three discussants, which helps to generate the requisite data. Findings reveal that convergence has significantly influenced broadcasting practice, and this influence is more positive than negative. The findings also show that media convergence creates additional and better opportunities, as more distribution channels for broadcast content emerge. These developments, however, may remain unsustainable if the stakeholders do not address the identified challenges appropriately. The government of Edo State can play a leading role in addressing those challenges.
\end{abstract}

Keywords: Broadcasting practice, convergence, new media, Edo State, Nigeria. 


\section{Introduction}

Homo sapiens do communicate to meet needs and maintain relationships (Baran, 2012; Biagi, 2012; Dominicks, 2015). They have, over time, devised various means to sustain this activity (Sambe, 2005; Gbam, 2017; Turow, 2017). Information dissemination has gone through seven phases since the discovery of the Egyptian papyrus at Mesopotamia in 3000 BC. These are the invention of language, typing/printing, the radio, television, computers, information/communication technologies (ICTs), and the internet (Emwinromwankhoe, 2018a; Turow, 2017).

The third and fourth phases birthed broadcasting, which, in its basic form, is the business of disseminating information to a broad, scattered and heterogeneous audience through electromagnetic waves. The traditional broadcast media (radio and television) indisputably held sway for decades as many persons from various parts of the globe relied heavily on them to keep abreast of current information (Biagi, 2012; Ngomani, 2016; Olowofela \& Peter, 2018). For instance, it was a common sight to find scores gather in a house to watch the Nigerian Television Authority (NTA) Network News at 9:00 p.m. or listen to the 7:00 a.m. news on the network service of Radio Nigeria.
When major sports competitions such as the World Cup or Olympics were on, it was common to see persons converge on strategic locations to catch the sights and sounds of the games.

Suffice it to say that going by the ephemeral nature of these media, the audience found it an incredibly impossible task to record the disseminated messages for future use. It was such that if one missed the 9:00 p.m. NTA Network News, then one had missed a whole lot as there were very slim chances of watching it in future - except the station, for some reason, decided to air it again. The dictum - 'the radio only speaks once' - was famous at the time. The content of these traditional media was mostly linear and unidirectional as the audiences became dumping grounds for news and reports.

In recent times, however, the status quo has changed. With the introduction of new media technologies such as the internet, laptops, smartphones, tablets, iPhones, iPods, Xbox, to name a few, as well as the proliferation of digital devices, there have been tremendous disruptions in the nature, structure, and landscape of broadcasting across the globe (Pavlik, 2005; Pavlik, 2015; Kalamar, 2016; Kipkirui, 2016). The old (or traditional) broadcast media and the new media have fused, giving birth to what is technically known as media 
convergence. As a consequence, the audiences of broadcast messages are no more dormant and have become citizen journalists or broadcast news 'produsers' (Erdal, 2007; Chao-Chen, 2013; Kalamar, 2016).

Today, there are no clear distinctions between private (telecommunication) and public (broadcasting) communication, nor are there distinctions between the character of the message or the equipment used to produce, transmit or receive the message (OECD, 2013). This development exists because such devices as the smartphone, an iPhone, or tablet are capable and available to record, edit, package, and disseminate a broadcast content.

Broadcast audiences also do not have to stay close to the "box" (radio set) in order to receive radio messages anymore, neither do they need to stay glued to their television sets in order to watch television programs (Adeyeye et al., 2020) With just a click on a device such as a smartphone, they can live stream the broadcast program online - even when they are miles away from their houses. The dictum that "the radio only speaks once" has been demystified as the news consumer can simultaneously listen to and record a broadcast, or download it and reuse it. The consumer in question can also visit YouTube weeks, months, or even years later, to access the uploaded content.

Uba (2017), a one-time DirectorGeneral of the Nigerian Broadcasting Commission captures the changes mentioned above succinctly with his remark:

I have witnessed incredible developments and changes. From queuing at a NITEL phone booth to make an international call, to waiting on NTA after school to commence broadcast at 4 p.m., $\quad \ldots$ to watching television on my cell phone, while my Netflix tells me what to watch next after The Wedding Party. I am incredibly lucky to be a witness to this new world, and it keeps growing even as it gets smaller and closer ... The world has changed, and it was televised. Digital innovation, changing social norms and the evolution of consumer behavior have revolutionized the audiovisual markets globally (p. 7)

It is worthy of note that of all the new technologies which have made those developments described above possible, the internet particularly stands out. The internet is unarguably the springboard for the transformations. It is the New Media's main circuitry (Olise, 2012; Olise \&Tabakaemi, 2015). 
This multimedia information superhighway, as Agba (2002) describes it, has completely revolutionized the entire process of producing and distributing broadcast content. The internet's capability of distributing information usable for broadcast programs is awe-inspiring (Owuamalam, 2008; Mathew, Ogedebe \& Abaya, 2013).

Taylor (2015), the SecretaryGeneral of the Commonwealth Telecommunications Organization, sums it up this way:

The internet today has become a viable delivery mechanism for audio and video broadcast services, whether it is live programs, social media, or ondemand services ... It provides consumers today with unprecedented opportunities - to choose how they watch the programs either through traditional 'linear' broadcast of a news bulletin or by instant access to individual news items as may be determined by the user rather than the news editor. (p. 14)

The internet, therefore, has made convergence possible. It has blurred the differences that exist between the old broadcast media and the new broadcast media and created a meeting point or an alignment for them. Thus, we not only have traditional radio and traditional television stations, but we also have internet radio and internet television. With convergence, local, national and international broadcast stations not only engage in traditional linear broadcasting but also have links through which their audiences can access their broadcast messages online.

Convergence has also triggered significant changes in the way and manner in which broadcast audiences consume content with the availability of new platforms and portable devices. Nowadays, broadcast messages can be provided on multiple platforms such as analog or digital terrestrial broadcasts, satellite, cable or Internet Protocol (IP), and Overthe-Top (OTT) television (Olley, 2009; OECD, 2013; Kipkirui, 2016). With convergence, the definition of broadcasting is rapidly changing (Erdal, 2007; Obaje, 2018).

As a result of the enormous transformations that convergence has brought to broadcasting, the attention of media scholars across the globe has increasingly been drawn to the influence of convergence on broadcasting practice (Pavlik, 2005; Khan, Shalid\& Ahmad, 2014). The debate is two-sided. Some scholars (Adoni \&Nossek, 2001; Menezes \& Carvalho, 2009; Chao-Chen, 2013; Turow, 2014; Taylor, 2015; Uba, 2017) argue that convergence has a 
positive influence on broadcasting practice. The premise of their argument is that convergence has led to more fabulous markets and higher profits for broadcast operators.

Some other scholars (Deuze, 2003; Pavlik, 2005; Khan, Shalid \& Ahmad, 2014; Kalamar, 2016; Kipkirui, 2016; McEwan, 2017), however, think that the influence convergence is negative. They contend that factors such as hypercompetition and increased consumer choices have led to a continuous decline in the profits of broadcast operators as a result of convergence. To this end, this study sought to investigate the influence of convergence on broadcasting practice in Edo State, one of Nigeria's 36 states.

\section{Statement of the Problem}

Convergence has triggered tremendous changes in the business and practice of broadcasting across the world, and Nigeria is not an exception. Its influence can be seen and felt in every facet: newsgathering, news writing and reporting, news packaging and design, and news dissemination. For instance, in a study carried out on Brila 88.9 FM, a Sports Radio in Kaduna State, Ogwuche (2017) discovered that convergence has tremendously influenced how programs are packaged and disseminated in the station. The broadcasting practice in Edo State of Nigeria is an archetype of these developments.

For some scholars (Adoni \& Nossek, 2001; Menezes \& Carvalho, 2009; Chao-Chen, 2013; Turow, 2014; Taylor, 2015; Uba, 2017; Ogwuche, 2017), the influence of convergence on broadcasting practice is positive as broadcast operators now have access to wider audiences and profits. Other scholars (Deuze, 2003; Pavlik, 2005; Khan, Shalid \& Ahmad, 2014; Kalamar, 2016; Kipkirui, 2016; McEwan, 2017) hold tenaciously to the view that the profits of broadcast operators keep plummeting, pointing to convergence as the primary cause of the problem. An investigation on the trends in Edo State of Nigeria presented an opportunity to explore further the context of convergence on broadcasting practice.

\section{Research Questions}

The following are the research questions that guided the study:

1) What is the influence of convergence on broadcasting practice in Edo State of Nigeria?

2) Does convergence promote the distribution of more broadcast content by practitioners in Edo State of Nigeria? 
Significance of the Study

This study is vital to broadcast practice in Edo State, the academia and the indigenes of Edo State. For broadcast practitioners, it will help them be in the know of the influence of convergence on broadcasting practice in Edo State. The knowledge gained on the subject could empower these broadcast practitioners to adequately adjust to the significant changes triggered by convergence and ultimately harness the potentials for seamless and improved broadcasting.

For academia, the study would update available literature, including the empirical studies carried out on the topic. It also would help keep Edo State indigenes abreast of the influence of convergence on broadcasting practice. If they are knowledgeable about the influence of convergence, they would be able to make informed decisions on how to access broadcast messages on different platforms.

\section{Literature Review}

\section{Understanding Convergence}

Convergence has been a central concept in contemporary broadcasting. As such, it has attracted definitions from numerous scholars and practitioners in the field of mass communication. Suffice it to say that each definition
CJOC (2020) 7(1) 26-52

is invariably shaped by each writer's perception as convergence, as a term, is very broad with multiple meanings and elusive. This diversity is why Latzer (2013) avers that convergence is an ambiguous term used by various disciplines to describe and analyze processes of change towards uniformity or union. Thus we have media convergence, industry convergence, legal convergence, economic convergence, sociocultural convergence, payment method convergence, energy consumption convergence, software convergence, amongst others (Chiariglione, 2013).

The word "convergence" is the nominalized form of the verb "converge," which is defined by the Oxford Advanced Learner's Dictionary ( $7^{\text {th }} e d$.) as "to move towards each other and merge at the same point." For instance, when we say persons have converged on a place for an event, it means that such persons have gathered or met at the same spot for the event (Okon et al., 2018). Etymologically, the word 'convergence' has its roots in the Latin words com, which means 'towards' and verger, 'to bend' or 'lean.'

Jonas (2004) defines convergence as a combination of many telecom technology and services in order to maximize 
market and industry barriers. Also, Killebrew (2005) sees convergence as a movement in the field of mass communications that binds previously competitive media delivery formats (platforms) to another.

According to Biagi (2012), convergence describes two developments taking place simultaneously. First, it means the melding of the communications, computer, and electronics industries because of advances in digital technology. Second, convergence means the economic alignment of different types of media companies with each other to make sure they can offer a variety of services that technical advancements demand.

Turow (2017, p. 44) adds his assertion, stating that "convergence is a phenomenon which takes place when products typically linked to one medium show up on many media." Turow accentuates this point, stating that it is like when you can get a Red Box baseball game broadcast in Boston to show up on your laptop computer and your android phone, or when you can transfer an Adele music album from your laptop to your iPod, iPhone, iPad, or Xbox. Similarly, Okoroafor (2016, p. 25) describes convergence as "the coming together of two or more distinct entities or phenomena, thereby removing entry barriers across the IT, telecoms, media and consumer electronic industries."

The above definitions point to one basic fact: convergence is the blending, melding, and merging of different media technologies and contents which were hitherto disparate and separate from each other. For example, when an Android phone is used in the production of text, video, and voice for broadcast purposes, or used in reading newspapers and magazines online, it is convergence.

However, as it pertains to the field of broadcasting, Taylor (2015, p. 14) offers a very comprehensive and acceptable definition. He says convergence "is the blurring of the hitherto three distinct industries of telecommunications, computers, and broadcasting.'

Emwinromwankhoe (2018b, p. 127) agrees with Taylor's stance and describes convergence as "the merging of the traditional media such as radio and television with new media technologies such as the Internet, satellite, mobile phones, etc. into one."

Convergence in broadcasting is of different types. Technological convergence is the ability of any infrastructure to package, process, and transport any type of data text, picture, audio, and video. Market convergence is the coming together of the telecommunications, 
computer, and broadcasting industries. Consumer convergence is the ability of a broadcast consumer to access content using a multiplicity of devices. Cultural/visual convergence means the capacity to merge voice and video with texts and photographs. Newsroom convergence is the process whereby news, features, news commentaries, and other related resources are shared within and between broadcast organizations. Regulatory convergence is the merging of the regulatory bodies for the telecommunications and broadcasting industries for efficient management processes.

\section{Convergence and Broadcasting Practice}

Media scholars the world over are unanimous in their views that convergence is shaping, affecting, and redefining the world's broadcasting landscape. For instance, Dominicks (2015, p. 263), after taking an in-depth look at recent trends in broadcasting in the United States of America, concludes that "broadcast television is in a state of change." According to Biagi (2012), Pavlik (2005), Jenkins (2006), Baran (2012), Pavlik (2015), and Kipkirui (2016), convergence has led to the reshaping of broadcasting in terms of content, nature, structure, organization, and delivery. Biagi (2012) notes that:

Within the last 30 years, the emergence of the internet as a media delivery system has transformed the structure and the economics of the media business in the United States and throughout the world ... Today, the internet delivers all types of media using a single delivery system without barriers. You can receive all types of media just about anywhere you want, delivered by many different types of companies, carried on invisible electronic signals you can't see (p. 187).

Convergence has led to the erosion of the differences that once existed among the media of communication (Pavlik, 2005; Fagerjord \& Storsul, 2007; Latzer, 2013; Baran, 2015). It has brought the hitherto disparate fields of telecommunications, broadcasting, and computers together and blurred the differences that exist among them (Pavlik, 2005; Turow, 2017; Taylor, 2015; Ngomani, 2016). According to Baran (2015), convergence in broadcasting is fueled by three elements which have come together almost simultaneously: 
(a) Digitization of nearly all information, which provides a standard means to represent all forms of communication.

(b) High-speed connectivity; networks are becoming faster and more pervasive - wired and wireless.

(c) Seemingly endless advances in technology in which speed, memory, and power improvements allow a device to do more. That redefines the limits to what is possible.

Baran (2015) and Turow (2017) posit that convergence in broadcasting has necessitated the blurring of the differences between content producers and content consumers. Traditionally, the producer in the broadcast business was a large, hierarchically structured broadcast organization such as CNN, Pixas Studios, NTA, and others. Today, however, blogs, social networking sites, websites, and the like have made broadcast consumers double as producers; hence the coinage produsers (Latzer, 2013; Baran, 2015; Turow, 2017). Baran (2015, p. 41) remarks that "today, 37\% of Internet users have contributed to the creation of news, commented about it, or disseminated it via postings on social media sites."

Oyero (2007), and Olowofela \& Peter (2018) assert that with convergence, radio and television stations have broken barriers in Nigeria as most smartphones used in the country have pre-installed radio and TV apps on which the audience access their content. The internet and social media are not left out of the equation as the stations also upload various online audio and videos which users can easily access.

In recent times, broadcast stations across the world deliver content via multiple platforms, which some scholars (Petersen, 2002; Fagerjord \& Storsul, 2007; Cordeiro, 2012) refer to as crossmedia. As Turow (2017) notes, not only do broadcast audiences consume content on different sites, they listen to and view content using different services. Turow (2017) emphatically states that:

If you subscribe to cable or satellite television, you probably know that the companies give you the possibility to view a variety of channels live or even ondemand just about anywhere through various devices your TV set, your desktop computer, your laptop, your tablet, your smartphone, your Xbox video game console, your Apple TV, and more (p. 42).

For instance, an international broadcast station like the BBC not only has channels through which its audience can live stream content 
via a multiplicity of media devices but has also made it possible for the audience to view and download its content on YouTube. Aside from these, the stations' reporters now produce both broadcast and print content (meant for posting on the stations' website) simultaneously.

The situation is not any different in Nigeria. Broadcast operators across the country now disseminate their messages using multiple platforms (Bisola et al., 2018; Oyero 2007; Emwinromwankhoe, 2018b; Ja'afaru, 2018; Olowofela $\&$ Peter, 2018). Stations such as ITV, NTA, Raypower FM, Silverbird Radio, Channels Television, TVC Nigeria, amongst others, have links through which consumers can access content online using a multiplicity of devices. These devices include smartphones, iPhones, iPad, tablets, laptops, advanced video game consoles, and lots more. Also, most of these stations simultaneously broadcast on digital terrestrial TV and cable TV.

Convergence is an ineluctable phenomenon in today's broadcasting practice. Convergence has come to stay, to transform, to reshape, redefine and restructure the practice of broadcasting. Broadcast operators in Nigeria in general and in Edo State, in particular, cannot afford to turn a blind eye to this hydra-headed giant whose influence on broadcasting is massive. This development is the reason Okoroafor (2016) strongly advocates the inclusion of special lectures on convergence in the curriculums of institutions that have mass communication or media studies disciplines in the country.

\section{Convergence and its Influence on Broadcasting Practice}

Convergence has significantly affected every aspect of broadcasting across the globe. Its influence is visible right from the process of gathering broadcast information through to the dissemination of such information to members of the public. Pavlik (2005) specifies such areas to include acquisition, production, distribution, display, and storage. Convergence has made it possible for broadcast practitioners to use sophisticated cameras and microphones in information gathering. Pavlik (2005) notes that this has two advantages: recordings do not degrade over time (b) information can be compressed for faster dissemination.

Today, broadcast practitioners use wireless and powerful microphones coupled with 3-D high-resolution cameras. The implications are that sounds and pictures are brighter, sharper, and can be stored for centuries without degradation. Many of the cameras 
used today are miniaturized, thereby making them very portable. Many microphones and cameras have editing capabilities as they capture and edit sounds and videos simultaneously. Also, broadcast reporters can use technological devices such as smartphones and tablets to record sounds and videos when they stumble upon newsworthy events when covering their beats. Those devices also come in handy when such broadcast reporters are miles away from their stations and deem it necessary to be the first to report the event to members of the public.

Convergence has also made it possible for broadcast practitioners to get first-hand news from news produsers. Albeit most scholars (Erdal, 2007; Biagi, 2012; Emwinromwankhoe, 2018b, Omojola, 2008a; Omojola, 2008b) argue that such news needs to be checked, double-checked, and triple-checked for accuracy, fairness, balance, and objectivity, the truth remains that news by these produsers, especially scoops, are vital to broadcast professionals. Furthermore, digital cameras can be attached to robots and remotely controlled for newsgathering operations. This proficiency saves time, reduces costs, and increases operational efficiency.

Also, broadcast production and post-production processes (such as editing) have witnessed an unprecedented transformation as a result of convergence. Nowadays, the processes of producing and editing broadcast programs are faster and more effective. For instance, newsroom convergence enables a broadcast journalist in a branch station to write, edit, and send news stories to the editor of another station for inclusion in the news bulletin. Also, powerful technological devices such as smartphones and tablets can be used to quicken the editing process as many of such devices have powerful editing tools.

Convergence has equally created more distribution channels for broadcast stations across the globe. Contents can be distributed via boundless means at higher speed and cheaper costs. For example, a station like ITV in Edo State distributes its contents via digital terrestrial broadcasting, cable TV (Startimes), and live streaming via various technological devices such as iPhones.

Convergence has also significantly affected the display of broadcast contents. The multimedia feature of convergence has now made it possible for a radio or TV station to combine audio, video, and texts as content (triple play). Some TV stations now display a combination of audio, video, text, and data (quadruple play). An 
international broadcast station like $\mathrm{CNN}$, for instance, relays videos, audio, texts, pictures, and animations (where necessary) for each news item on its online platform. With regards to storage, convergence has made it possible for broadcast contents to be stored on a variety of devices such as flash drives, DVDs, personal and digital video recorders, as well as online. Such contents can be stored for a long time without degradation.

\section{Challenges of Nigerian Broadcast Practitioners in the Era of Convergence}

Owing to convergence in broadcasting, Nigerian broadcast practitioners now grapple with some challenges. First, there is a lack of training on the use of new media. Many broadcast practitioners in Nigeria do not have an in-depth knowledge of how to use the new media for broadcast purposes. Nwanne (2016) notes that many Nigerian broadcast journalists were trained on typewriters and other analog devices, while some are not digital enthusiasts. Moreover, there are erratic power supply problems in many parts of Nigeria. The privatization of the electricity industry has not led to an improvement in energy supply. Since virtually all new media need a stable or uninterrupted power supply to function, inadequate power supply constitutes a significant impediment to broadcast professionals in the era of convergence.

The high cost of acquiring new media systems constitutes another challenge. Poverty is still a problem in Nigeria and other developing countries (Olise, 2012; Nwanne, 2016). Most new media such as smartphones, tablets, and laptops are sold at high prices with little or no subsidization from the federal or state governments. The recession did not help matters as it made the already high costs to escalate further. Consequently, many broadcast practitioners are unable to afford new media devices.

Inadequate Internet facilities is another challenge. Many a broadcast professional considers it a Herculean task to access information using an Internet network that does not fluctuate (Morah \& Omojola, 2014). Even with the introduction of the $4 \mathrm{G}$ network by the majority of the network service providers in the country, the situation has remained uninspiring as many broadcast practitioners can hardly get $3 \mathrm{G}$ workable on their new media devices, let alone 4G. Since broadcasting is time-bound and much more with convergence, inadequate Internet facilities constitute an impediment to breaking the news. 
Furthermore, there is the difficulty in verifying the authenticity of the news source(s). Because converged broadcasting has opened the door for citizen journalists or news produsers to thrive, verifying the authenticity of the news source(s) is a challenge for many broadcast practitioners in Nigeria. This is so because the internet is continuously laden with several broadcast contents about people, events, and places. Therefore, it has become tough knowing which report is accurate and which is false (Okorie, Loto \& Omojola, 2018; 2011; Folayan et al., 2018).

Lastly, it is not fitting that many broadcast stations, particularly those owned by the federal and state governments, are bereft of new media technologies. In the very few stations where such new media are available, they are either outdated or inadequate. Even with the endless calls by the National Broadcasting Commission (NBC) and the Broadcasting Organization of Nigeria (BON) that all broadcast stations in the country should fully embrace digitalization, many government-owned stations still operate the analog broadcasting systems. This is a great challenge because it is only when new media technologies are available that broadcast professionals can put them to good use.

\section{Review of Related Empirical} Studies

Several empirical studies exist concerning the influence of convergence on broadcasting practice. For instance, Dupagne \& Garrison (2003) carried out a study to investigate the effects of convergence on Media General's Tampa News Center in Florida, USA. The researchers found that jobs and roles in the center have changed due to convergence and that staff members think more about how to disseminate information than before.

Olley (2012) also conducted a study to find out the influence of new media technologies on broadcasting practice in four stations in Edo and Delta States of Nigeria. Findings showed, among others, that new media technologies have tremendously influenced the practice of broadcasting in the stations. Similarly, Mwaura (2011) conducted a study to ascertain the impact of the new media on radio broadcasting on Capital FM radio, Kenya. Findings revealed that the staff of Capital FM Kenya significantly used new media platforms during the gathering, processing, and broadcasting of content, and the station's audience now has more options as to how to consume these contents. Mwaura's findings were corroborated by Adigwe (2012), whose study, 
among other things, revealed that information and communication technologies (ICTs) had affected news processing, reporting, and dissemination in broadcast stations in Lagos State, Nigeria.

Meier, Bracker \&Verhovnik (2016) embarked on a study to unravel the challenges faced by the over 5,000 employees of Bavaria's Public Broadcasting Service, one of Germany's largest media organizations, in the era of convergence. The researchers found that the absence of networking (particularly crossmedia), absence of flexible workflow design possibilities; problems with the use of mobile devices in media production; and insufficient integration of social media in research constitute challenges faced by the employees in the era of convergence.

In the same vein, Ngomani (2016) conducted a comparative study to ascertain radio listening habits among young people in Cape Town, South Africa, in the era of convergence. The study focused on three stations in Cape Town Assembly Radio, Cliff Central, and Balls Visual Radio. Findings from her study revealed that radio listening habits among young people living and studying in township significantly differ from the practices of those who attend school in rural areas.

\section{Theoretical Framework}

\section{Technological Determinism}

Theory

The term "technological determinism" was coined by Thorstein Veblen (1857-1929), an American sociologist-cumeconomist. Technological determinism revolves around the proposition that technology in any given society defines the society's nature as well as culture (Nwanne, 2016; Asemah, Nwammuo \& Uwaoma, 2017; Uwawah, 2018). As noted by Nwanne (2016) and Ja'afaru (2018), technological determinism theory rests on the underlying assumption that technology is what determines, shapes and influences how people in a society think, believe and behave. Technological determinism theory sees the media as the main force behind social and cultural changes in society. Technologies shape our society. They sure determine how we think, how we talk, how we act, how we socialize, how we produce, package, deliver, and consume information. The theory helps to relate this study to the situation in Edo State of Nigeria, which is the focus of this study.

\section{Mediamorphosis Theory}

Roger Fidler propounded Mediamorphosis theory in 1997. The theory is a convergence and 
technology-based theory (Uwawah, 2018). Mediamorphosis theory claims that media, technology, and communication practices are all interconnected and that it is the technology that drives development in the field of communication. Elucidating the mediamorphosis theory, Fidler (1997) cited in Uwawah (2018) remarks that:

New media do not arise spontaneously and independently - they emerge gradually from the metamorphosis of old media. Older forms do not die; they continue to evolve and adapt. Established forms must change in response to the emergence of a new medium - their only option is to die (p. 20).

The fundamental principles of the theory include: (a) co-evolution and co-existence of all new and old media (b) the mediamorphosis of old media into new ones (c) survival of old media amid new ones (d) opportunities presented by new media and the needs they meet.

The theory is pertinent to this study because it would help explain how the traditional broadcast media in Edo State have metamorphosed into new broadcast media. It would also help describe the influence this metamorphosis (or convergence) has on broadcasting practice in the state.

\section{Methodology}

The study adopted the mixed research method, which comprised both the quantitative (survey) and the qualitative (interview) methods. It used the questionnaire and an interview guide as research instruments. The test-retest technique was employed to ensure the reliability of the instruments. The population of the study comprised the staff of the three broadcast stations - NTA, Edo Broadcasting Service (EBS), and ITV/Radio - that were studied. From the information obtained from the stations' management, there are 84 staff members in NTA; 145 in EBS; and 150 in ITV/Radio, totaling 379 . This figure formed the population of the study, and nearly all of them had a good understanding of the subject matter.

A sample size of 100 staff was arrived at, using the Taro Yamane's (1967) formula. Still going by the same formula, 22 staff received a questionnaire in NTA, Benin; 38 did so in EBS while 40 did so in ITV. Simple random sampling was adopted in selecting the 100 staff members who received the questionnaire in the three stations. In contrast, the purposive sampling technique was used in selecting three notable broadcasting experts who were interviewed. They included the Manager of Programs, NTA Benin; the Public Relations 
Officer, EBS; and the Controller of Programs, ITV. The questionnaire was administered on a person-toperson basis. In effect, the completed questionnaire (100 in number) was collected on the spot from each of the respondents.

\section{Data Presentation and Analysis}

Bar charts are used to illustrate the results of the analysis. The choice was necessitated by the need for the researcher to make the outcome of the investigation vivid.

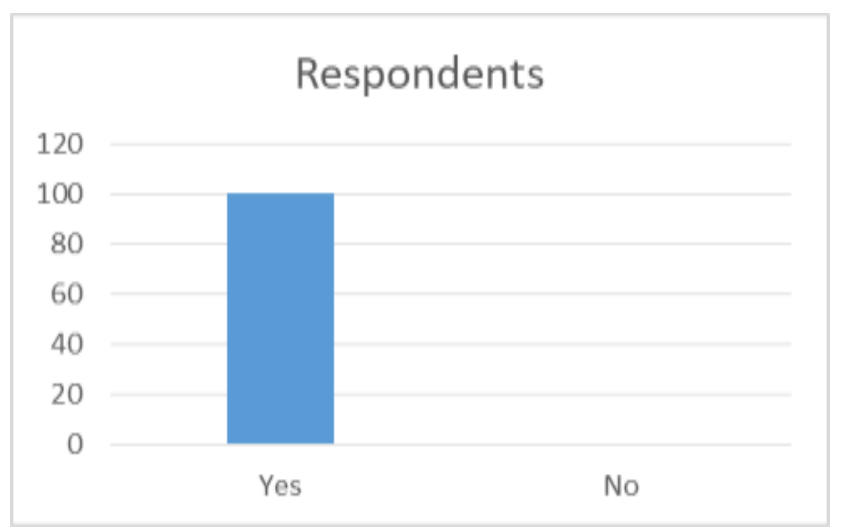

Figure 1: Whether convergence has influenced broadcasting practice in Edo State

Figure 1 indicates that convergence has influenced broadcasting practice in Edo State as all of the respondents (100\%) answered "Yes" to the question. 


\section{Respondents}



Figure 2: Extent to which convergence has influenced broadcasting practice in Edo State

The data in Figure 2 reveal that broadcasting practice to a great convergence has influenced extent (88\%) in Edo State.

\section{Respondents}

100

80

60

40

20

0

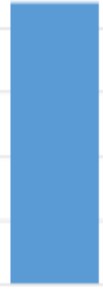

Positive

Negative

Can't tell

Figure 3: The kind of influence convergence has on broadcasting practice in Edo State

URL: http://journals.covenantuniversity.edu.ng/index.php/cjoc 
The data in Figure 3 indicate that convergence $(88 \%)$ has a positive influence on broadcasting practice in Edo State.

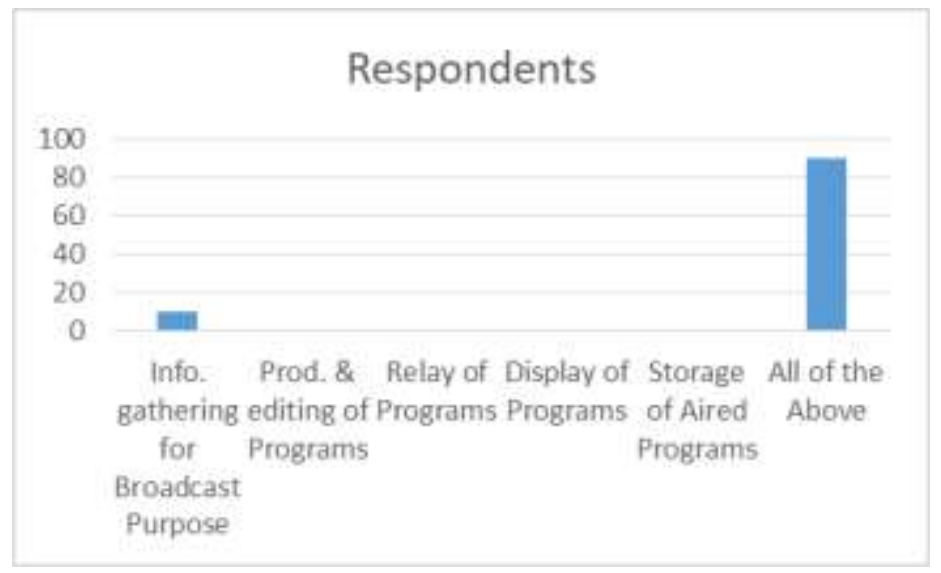

Figure 4: Areas in which convergence has influenced broadcasting practice in Edo State

The data in Figure 4 reveal the areas in which convergence has influenced broadcasting practice in Edo State. The data show that convergence has influenced broadcasting practice in all of the above ways $(90 \%)$.

\section{Respondents}



Figure 5: Whether convergence has led to more avenues for the distribution of contents by practitioners in Edo State 
The data in Figure 5 indicate that convergence ( $88 \%$ ) has led to led to more avenues for the distribution of contents by broadcast practitioners in Edo State.

\section{Discussion of Findings}

Research Question 1: What is the influence of convergence on broadcasting practice in Edo State?

The study shows that convergence has influenced broadcasting practice in Edo State to a significant extent. This is evident in Figure 2, where the majority $(88 \%)$ of the respondents showed up in that light. The three interviewees were also unanimous in their views that convergence has greatly influenced broadcasting practice in Edo State. While making useful references to the practice in their broadcast stations, the interviewees strongly asserted that convergence has enormously influenced broadcasting practice in Edo State.

This finding is in tandem with those of Dupagne \& Garrison (2003), Olley (2009), Mwaura (2011), Adigwe (2012), Ngomani (2017) and Ogwuche (2017). It also upholds the central tenets of the technological determinism as well as mediamorphosis theories. The influence the new media exert on the broadcasting practice in Edo State is such that the traditional broadcast media are rapidly mediamorphosing due to convergence.

The areas in which convergence has influenced broadcasting practice in Edo State include the gathering of information for broadcast purposes, production and editing of programs, relay of programs, display of programs, and storage of broadcast programs. From the in-depth interviews conducted, there was a convergence of opinions that convergence has influenced broadcasting practice in Edo State in many areas. The interviewees also agreed that some such areas include speed, editing, relay, and storage of broadcast contents. The Controller of Programs, ITV asserted that:

With convergence, an editing suite is no longer a room or building as a smartphone can constitute an editing suite. Convergence has also impacted on storage as the hard drive, DVD tapes, etc. are now used to store broadcast contents. These devices are an improvement on the VHS tape, which was very much in vogue years ago.

This finding aligns with the views of some scholars (Pavlik, 2005; Pavlik, 2015; Ja'afaru, 2018), it also upholds the findings of Olley 
(2009), Mwaura (2011), Adigwe (2012), Meier, Bracker \& Verhovnik (2016) and Ogwuche (2017). Suffice it to say that the finding also supports the underlying assumption of the technological determinism theory that technologies shape and affect everything about the mass media from newsgathering to the storage of media contents.

The findings also show that convergence has a positive influence on broadcasting practice in Edo State. This conclusion is based on the opinions of most of the respondents $(88 \%)$ who agreed that convergence has positively influenced broadcasting practice in Edo State. The three experts interviewed first noted that convergence has both positive and negative influences on broadcasting practice before concluding that the influence is more positive than negative. The following are the words of the Public Relations Officer of EBS:

Convergence has both a positive and negative influence on broadcasting practice in Edo State. For instance, broadcast stations now have wider access to information, enriched content, as well as enhanced feedback.

Negatively, however, there is acculturation as many persons in the state in particular and the country in general have and are still copying the culture of the west, such as indecent dressing, drug use, gangsterism, watching of pornographic movies, rape, kidnapping, militancy, etc. However, I think convergence has more of a positive influence than a negative one on broadcasting practice.

These findings do strengthen the assertions of some scholars (Adoni \&Nossek, 2001; Menezes \&Carvalho, 2009; Chao-Chen, 2013; Taylor, 2015; Turow, 2017; Uba, 2017) and corroborate those ofDupagne\& Garrison (2003), Meier, Bracker \&Verhovnik (2016) and Ogwuche (2017).

\section{Research Question 2: Has convergence led to more avenues for the distribution of contents by broadcast practitioners in Edo State?}

The study shows that convergence has led more avenues for the distribution of content by broadcast practitioners in Edo State. This is because 88 percent of the respondents answered in that light. Similarly, all the experts interviewed agreed that convergence has led to more avenues for the distribution of contents by broadcast practitioners in Edo State. The Controller of Programs at ITV/Radio notes that: 
Convergence has opened more windows for the distribution of contents to Edo State broadcast stations, particularly private stations like ITV. With convergence, broadcast stations now generate more profits as their contents, aside from being accessed on radio and TV sets can be live streamed and relayed on Satellite or Cable TV.

The finding aligns with the assertions of many scholars (Adoni \&Nossek, 2001; Menezes \& Carvalho, 2009; Chao-Chen, 2013; Taylor, 2015; Turow, 2017; Uba, 2017). It is also parallel to the findings of Dupagne \& Garrison (2003), Olley (2009), Mwaura (2011), Adigwe (2012), and Ogwuche (2017). This supports one of the critical principles of the mediamorphosis theory opportunity and need. This is because converged broadcasting has unarguably created better opportunities (or avenues) for broadcast stations in the state to distribute content to their various audiences.

\section{Conclusion and}

\section{Recommendations}

Convergence has significantly influenced broadcasting practice in Edo State. This influence is evident in all areas of broadcasting practice, which range from the acquisition of information to the storage of content for future use. Since convergence has led to more avenues for the distribution of contents by broadcast practitioners in Edo State, the implication is that convergence has a positive influence on broadcasting practice in the state.

Nevertheless, convergence - like the proverbial rose flower - has come with some thorns in the form of challenges faced by many a broadcast practitioner in Edo State. Therefore, to ensure seamless and enhanced broadcasting in the era of convergence, these challenges should be adequately tackled. The following recommendations proceed from these discussions and findings:

- Edo State Government should make efforts to ensure the provision of stable power supply in the state. This is important because virtually all new media depend on power supply to function effectively. The Government could partner with the Federal Government in this regard.

- Edo State Government should help subsidize the prices of new media such as smartphones, iPads, and the like so that Edo State broadcast practitioners can easily afford them.

- Owners of broadcast stations in Edo State should make it a 
point of duty to upgrade their facilities with new media technologies.

- The management staff of broadcast stations in Edo State should, from time to time, conduct training and skill acquisition programs for their employees on the use of new media.

- Broadcast practitioners across Edo State should make

\section{References}

Adeyeye, B., Amodu, L., Odiboh O., Omojola, O., Adesina, E. \& Ben-Enukora, C.A. (2020). A SWOT analysis of indigenous language use in agricultural radio programming in Nigeria. In N. Okorie (ed), emerging trends in indigenous language media, communication, gender, and health. Hershey, PA: IGI Global, pp. 188-209.

Adigwe, I. (2012). The impact of information and communication technology (ICT) on news processing, reporting and dissemination in broadcast stations in Lagos, Nigeria. Library Philosophy and Practice (EJournal). Retrieved from http://www.digitalcommons. unl.edu/libphilprac. tenacious efforts to verify information obtained from the internet, social media as well as those from citizen journalists before relaying them. They should check, double-check, triple-check, and even quadruple-check them in order to sieve the facts from fictional information.

Adoni, H.\&Nossek, H. (2001). The new media consumers: Media convergence and the displacement effect. The European Journal of Communication Research, 26 (1), 59-83.

Asemah, E., Nwammuo, A. \&Uwaoma, A. (2017). Theories and models of communication. Jos: Jos University Press.

Baran, S. J. (2012). Introduction to mass communication: Media literacy and culture $\left(7^{\text {th }}\right.$ ed.). New York: McGraw Hill, Inc.

Biagi, S. (2012). Media/Impact: An introduction to mass media (10 $0^{\text {th }}$ ed.). Belmont: Wadsworth Cengage Learning.

Bisola, K.B., Omojola, O., Oyero, O., Okorie, N., AdedejiKayode, T. (2018). 
Leveraging entrepreneurship for innovation in a developing economy. Proceedings of the 31st International Business Information Management Association Conference, IBIMA 2018: Innovation Management and Education Excellence through Vision 2020, pp. 6978-6983.

Chao-Chen,

L.

(2013).

Convergence of old and new media: New media representation in traditional news. Chinese Journal of Communication, 2(6), 103201.

Chiariglione, L. (2013). The future is more media convergence. The Journal of the Institute of Image Electronics Engineers of Japan, 42(3), 336-339.

Cordeiro, P. (2012). Radio becoming r@dio: Convergence, interactivity and broadcasting trends in perspective. Participations Journal of Audience \& Reception Studies, 9(2), 492510.

Deuze, M. (2003). The web and its journalisms: Considering the consequences of different types of new media online. New Media and Society, 5(2), 203-230.
Dominicks, J. (2015). Dynamics of mass communication: Media in transition $\left(12^{\text {th }}\right.$ ed.). New York: McGraw Hill, Inc.

Dupagne, M. \& Garrison, B. (2003). A case study of media convergence at Media General's Tampa News Centre. A Paper Presented at the Expanding Convergence: Media Use in a Changing Environment Conference, University of South Carolina, November 6-8.

Emwinromwankhoe, O. (2018a). Perception of Internet news among undergraduates of mass communication in University of Benin, Edo State, Nigeria. Novena Journal of Communication, 8, 198-207.

Emwinromwankhoe, O. (2018b). An appraisal of issues confronting the Nigerian broadcasting sector in the era of convergence. Benin Mediacom Journal, 12, 125135.

Erdal, I. J. (2007). Researching media convergence and cross media in news production: Mapping the field. Nordicom Review, 28(2), 51-56.

Fagerjord, A. \&Storsul, T. (2007). Questioning convergence. In T. Storsul \& D. Stuedahl (Eds.). Ambivalence Towards Convergence: Digitalization 
and Media Change (pp. 1931).

Folayan, B.J., Omojola, O., Egharevba, M., Oyesomi, K., Yartey, D \& Adeyeye, B. (2018). The use of ICTrooted communication codes and slangs among Nigerian students. The Journal of Social Sciences Research, 4(12), 633-641.

Gbam, B. N. (2017). The challenges and prospects of new media in public service broadcasting in Nigeria. Global Journal of Arts, Humanities and Social Sciences, 5(3), 1-7.

Hornby, A. S. (2005). Oxford advanced learner's dictionary ( $7^{\text {th }}$ ed.). Oxford: Oxford university Press.

Ikpefan, O.A., Ibinabo, H., Osuma, G.O., \& Omojola, O (2020). relationship marketing and deposit mobilization in five deposit money banks in Nigeria. Academy of Strategic Management Journal, 18 (6), 1-15.

Ja'afaru, S. G. (2018). Level of utilization of information and communication technology (ICT) tools for newsgathering by journalists in Jos, Plateau State, Nigeria. Novena Journal of Communication, 8, 158-167.
Jenkins, H. (2006). Convergence culture: Where old and new media collide. New York: New York University Press.

Jonas, L. (2004). The convergence hype cycle: Usage in management practice during an

impending market redefinition. A Paper Presented at the ITS Biennial Conference, Berlin, September 5-7.

Kalamar, D. (2016). Convergence of media and transformation of audience. Informatol, 49, 190-202.

Khan, G. A., Shalid, M. K. \& Ahmad, S. F. (2014). Convergence in broadcasting and telecommunication regulatory framework in Pakistan. International Journal of Management and Commerce Innovations, 2(1), 35-43.

Killebrew, K. C. (2005). Managing media convergence: pathways to journalistic cooperation.

Ames (IA): Blackwell Publishing.

Kipkirui, K. (2016). The benefits and challenges of converged journalism in the Kenyan media industry. Scholarly Journal of Science Research and Essay, 5(2), 36-42.

Latzer, M. (2013). Media convergence. A Working 
Paper of the Media Change $\&$ Innovation Division, University of Zurich, Switzerland. Retrieved from http://www.mediachange.ch/ media/pdf/publications.

Mathew, J., Ogedebe, P. \& Abaya,

F. (2013). Internet usage among broadcast media practitioners in Nigeria. New Media and Mass Communication, 17, 42-48.

McEwan, R. (2017). Renegotiating radio work in the era of media convergence:

Uncertainty,

individualization and centrality of brands. The Political Economy of Communication, 5(2), 45-66.

Meier, K., Bracker, I. \& Verhovnik, M. (2016). Technological innovation and convergent journalism: Case study of the transformation process of Bavaria's Public Broadcasting Service. Mediterranean Journal of Communication, 8(1), 33-44. Menezes, E. \&Karvalho, R. (2009). Impacts of new technologies on free-to-air TV industry: Lessons from selected country cases. Journal of Technology Management and Innovation. Retrieved from http://www.dx.doi.org.

Morah, N. \& Omojola, O. (2014). Digital large screens as a community medium: interactivity and community relevance in focus. In $A$. Ojebode (Ed.) Community Media in Nigeria. Ibadan: John Archer Publishers, pp. 385-402.

Mwaura, J. (2011). The impact of new media on radio broadcast: Case study of Capital FM (Kenya). Germany: Green Verlag.

Ngomani, N. (2016). Radio Convergence: Young people's radio listening habits in Cape Town. An Unpublished M.A. Dissertation Submitted to the Faculty of Humanities, University of Cape Town.

Nwanne, B. (2016). Journalism and new media in Nigeria: Issues, challenges and prospects. International Journal of Academic Research and Reflection, 4(3), 86-92.

OECD (2013). Competition issues in television and broadcasting. Paris: OECD Publishing.

Ogwuche, P. O. (2017). Adoption of convergence technology for sports journalism: A study on

Brila 88.9 FM. An Unpublished M.A. Dissertation submitted to the School of Postgraduate 
Studies, Ahmadu Bello

University.

Okon, P.E., Ajiboye, E., Ekanem,

T. \& Omojola, O. (2018).

Gendered News Reportage?

A study of The Guardian and

The Sun newspapers,

Nigeria. International

Journal of Media,

Journalism and Mass

Communications, 4(3), 2135.

Okorie, N., Loto, G. \& Omojola, O. (2018). Blogging, civic engagement, and coverage of political conflict in Nigeria: A study of Nairaland. com. Kasetsart Journal of Social Sciences 39 (2), 291-298.

Okoroafor, O. (2016). Media convergence: A paradigm shift in journalism education in Nigeria. Review of Journalism and Mass Communication, 4(1), 19-42. Olise, F. P. (2012). Computermediated communication and the challenges before users in Nigeria. In M. Mboho\& H. Batta. (Eds.). The Companion to Communication and Development Issues (pp. 373-391). Uyo: Department of Communication Arts.

Olley, O. W. (2009). New media technologies and their challenges to broadcasting in Nigeria. An Unpublished M.A. Dissertation Submitted to the School of Postgraduate Studies, University of Nigeria.

Omojola, O. (2008a). Toward Global Ethics: Exploring the Perspectives of Local Media Stakeholders. Ecquid Novi: African Journalism Studies, 29 (2), 173 - 187.

Omojola, O. (2008b). Audience Mindset and Influence on Personal Political Branding. Journal of Social Sciences (of India), 16 (2), 127-134.

Omojola, O. (2011) The press and the multi-level determination of public interest in a developing Society. In A. Alao and R. Taiwo (eds.) Perspectives on African studies: Munich: Lincom Academic Publishing, pp. 350-365.

Olowofela, A. D. \& Peter, A. S. (2018). Radio broadcasting and political development in Nigeria. Novena Journal of Communication, 8, 177-186.

Owuamalam, E. (2008). Elements of broadcasting. Owerri: Top Class Agencies Ltd.

Oyero, O. (2007). The implications of internet on the media and the practice of mass communication.

International Journal of Communication, 6, 169-174.

Pavlik, J. V. (2005). Understanding convergence and digital 
broadcasting technologies for the $21^{\text {st }}$ century. NHK Broadcasting Studies, 4, 131-138.

Pavlik, J. V. (2015). Transformation: Examining the implications of emerging technology for journalism, media and society. Athens Journal of Mass Media and Communications, 1(1), 9-24.

Sambe, J. A. (2005). Introduction to mass communication practice in Nigeria. Ibadan: Spectrum Books Limited.

Taylor, S. (2015). Why convergence of broadcasting, telecommunication shouldn't be ignored, Nigerian Guardian, 14 September. Turow, J. (2017). Media today: Mass communication in a converging world ( $6^{\text {th }}$ ed.) New York: Routledge.

Uba, E. (2017). Broadcasting and convergence: The future of TV and regulatory policies. Signal, 14 July.

Uwawah, A. (2018). Information communication technologies and theatre for development: Availability and use of modern tools. Benin Mediacom Journal, 12, 1829. 